\title{
Sharing Costs and Benefits of Energy and Resource Activity: A new book by SEERIL's Academic Advisory Group
}

Lila Barrera-Hernández is an international development consultant and Adjunct Associate Professor at the Univerity of Calgary, Canada, email lilakbh@gmail.com; Barry Barton is a Professor of Law at the University of Waikato, New Zealand, email barry.barton@waikato.ac.nz; Lee Godden is Director of the Centre for Resources, Energy and Environmental Law at the University of Melbourne, Australia, email l.godden@unimelb.edu.au; Alastair Lucas is Professor of Law at the University of Calgary, Canada, email alucas@ucalgary.ca; Anita Rønne is Associate Professor in Energy Law at the University of Copenhagen and Chair of the Danish Energy Law Society, Denmark, email anita.ronne@jur.ku.dk.

The Academic Advisory Group of the Section on Energy, Environment, Natural Resources and Infrastructure Law of the International Bar Association has produced a new study. It is presented in: Lila Barrera-Hernández, Barry Barton, Lee Godden, Alastair Lucas, and Anita Rønne, eds, Sharing Costs and Benefits of Energy and Resource Activity: Legal Change and Impact on Communities (Oxford University Press, 2016).

The study argues that a new phase is emerging in the relationship between energy and resource activities and the communities that are affected by them. It has become clear that the laws and regulatory frameworks that govern energy and resource projects in their interaction with communities are undergoing change. The existence of a new phase was evident in presentations at the biennial SEERIL conference in Berlin in 2014, and the AAG resolved to explore the ideas involved. It set itself a research objective of understanding the changing legal framework in which energy and resources activities bring benefits to communities but also impose costs on them. It presented the results of the research brought together in this book at the 2016 SEERIL conference in New York.

Law for many years has mediated impacts on communities through compensation regimes, assigned risk and liability, and provided legal measures for the distribution of financial benefits. Now, communities see more clearly that they have a stake in arrangements that deal with risk but which may affect their rights. Effects on local communities may cover a spectrum from negative consequences such as environmental damage, loss of amenity, social and cultural dislocation, and economic disruption, to more positive outcomes such as benefit packages promoting health, education and cultural outcomes, revenue flows, and jobs. The effects can also be more far-reaching than impacts around the immediate site of the project as regional, national, and transnational tensions may play out against the backdrop of energy and resource projects expanding the scale at which the impacts and benefits on communities need to be considered.

Many of these changes can be captured under the concept of sharing the costs and benefits of energy and resource activity. Indigenous peoples, and local communities faced with new technologies, for example, now seek active engagement in determining how costs and benefits are to be shared. 


\section{Costs and Benefits}

Identifying and providing redress for costs, impacts, or harms suffered is integral to many areas of law. There are a number of situations in which the costs and benefits of energy and resource activity are unevenly distributed or where activities may largely avoid the costs resulting from localized impacts due to inadequacy of the laws. 'Costs' include risks of environmental and community harm from energy projects, such as oil spills, explored in national law by Nigel Bankes and Astrid Kalkbrenner (Chapter 12) and by Catherine Redgwell (Chapter 4) in international law.

'Benefits' in the form of energy and raw materials are widely distributed through national and international economies contributing to the well-being of many people. Inequalities exist, however, in that distribution of energy and raw materials regionally and globally, as well as in the financial benefits obtained from energy and resource activities. From a legal standpoint, the most obvious benefits that accrue from a project such as a mine, a petroleum development, or a wind farm are the commercial revenues obtained by the company that undertakes the activity and subsidiary services. Special arrangements may be made for shares or other stakes in a project to be sold or issued to members of the local community. Nonetheless, communities may still contest the values that prioritize the private, commercial, and often multinational gains from these activities. On the other hand, the possibilities for collective and community funding of projects to achieve both financial and utility benefits to communities are rapidly being explored. Yet, many groups, such as indigenous peoples, remain excluded from the market economy generated by energy and resource activity, or are marginal participants in it.

Increased employment and business opportunities are another kind of benefits. Corporate social responsibility objectives play a major role, but increasingly training, education, and employment packages for local communities may be a legal requirement. Benefits can extend to provision of infrastructure, schools and hospitals. Benefits include the 'economic rent' from mineral resources and energy sources. Often, governments seek to obtain it for the public through royalties or special mineral taxes, but it can be asked, which level of government should extract these revenues, and how are they to be distributed and spent?

\section{Community}

Communities may be spatially defined, or ethnic, status, or interest-based. Communities are neither fixed nor incontestable. Barton and Goldsmith (Chapter 2) and del Guayo (Chapter 3) show that a community - its character, boundaries, and membership - is related to particular political choices in its constituency. Community involves not only shared identity, but to varying degrees, also the sharing of resources. Distributional justice issues around 'sharing' may resonate within a community based in bonds of trust and personal relationships but may also imply not sharing with outsiders. Thus, the processes of definition of a community and the exercise of power within a community may play out in the distribution or sharing of costs and benefits. Indeed, many energy and resource projects may prove to be highly divisive for 'local' communities and may lead to group conflicts.

The positive resonances of the idea of community should not be a shield that prevents rigorous examination of the extent to which arrangements for community benefits from energy and resources activity produce results that are just, equitable, and democratic or culturally appropriate. These considerations highlight the need for careful exploration of what it may mean to 'share benefits'. 


\section{Sharing}

Sharing could well be labelled allocation; and it imports ideas of fairness and distributive justice. Landowners may gain benefits in selling or renting land to the developer company. For example, the owners of isolated windswept hilltops in some regions have benefitted enormously when their land is identified as a prime wind energy site. The adoption of mineral taxes and royalties involves issues of distributive justice and reflects divergent views on whether energy and resources are a private benefit or a form of 'common property' to be used in the public interest. Should there be special rules for sovereign wealth funds? How should revenue be spread between the different levels of government? 'Benefit sharing' has emerged as a separate area in energy and resources law, as the allocation of economic as well as socio-cultural and environmental advantages. Yinka Omorogbe (Chapter 15) analyzes the difficulties around benefit sharing in Nigeria. Benefit sharing operates at international law, for example, REDD+ projects. It can amount to the subsidization of projects outside the financial donor state or organization in order to mitigate environmental, social, and cultural impacts. In many countries, benefit-sharing operates in concert with moves towards deliberative democracy or collaborative governance.

Sharing has come to the fore in both resource extraction and renewable energy contexts. In the case of a wind farm, there are benefits in increased national power capacity and reduced global greenhouse gas emissions, but they are very widely dispersed. In the eyes of the local community this may not offset the more immediate costs the project imposes on them. Equally, a mining project can bring prosperity and opportunity to its region, but often the local district experiences losses in poverty, social disturbance, political and cultural disruption, and environmental damage. Centre-periphery imbalances in sharing can arise where resource and energy wealth produced from a region or nation is 'exported' with minimal benefits remaining to support the local communities. This can weaken economic growth, cause conflict, and damage democracy. The stronger integration of isolated areas into national economies has given some communities greater capacity to question the distribution of costs and benefits.

The injustice of skewed distributions of resource wealth has caused instability in many resource-rich countries. The risks are higher where government is ineffectual in distributing benefits fairly, or where effective governance is absent in regions of a country. How costs and benefits are shared is therefore a serious question.

So, taking these emerging ideas and applying leading edge legal design, a new model emerges. This change is particularly striking when we begin with the old model that we recognize immediately.

\section{The Old Model}

The old model is the set of laws that we have become accustomed to for energy and resource management. It still exists, it is simply being overlain with the new one. As to costs, the old model addresses them with laws for environmental protection, mitigation of impacts, and internalization. In other words the allocation of costs or burdens through regulation, liability rules, and compensation. This was all a form of cost allocation. In particular, the company would have to pay. These laws have more or less become standard.

As for benefits, the old model allocates the benefits of resource development through royalties or special mineral taxes, usually at a state or national government level, and 
through the relevant private arrangements for the allocation of commercial profits. Royalties are usually taken at a high level, by the state, the national central government or in federal systems by a state or province. Royalty revenues go into government coffers, whether for general purposes or for a heritage fund. Commercial benefits are shared as revenue and profits as required as a matter of private arrangements. This set of laws has become a familiar pattern in many jurisdictions. But it no longer explains what we see now.

\section{Causes, Catalysts, Drivers}

The apparent causes of the new awareness of the allocation of resource benefits and costs are diverse.

- Higher global population and demand for resources.

- New technology for resource extraction (eg shale oil and gas with hydraulic fracturing) putting energy activity into regions where it had not occurred before.

- Reinvention of energy systems because of climate change response (eg renewable electricity; the new transmission lines needed for a new grid; and carbon capture and storage.

- Easier communication and transport, so that hinterland populations are less isolated and better informed. People are better educated. The heartland and hinterland are now better connected.

- Increasing integration of local and indigenous communities.

- There is a stronger critique of resource and energy companies and their relationships with governments, with connections to concepts of corporate social responsibility and social licence to operate.

- International law has emphasized sharing of the benefits of resources in many situations.

- The political character of the nation-state is more complex that it was. The forces of federalism, regionalism, decentralization, localism, nativism, populism and anti-globalism are more powerful than hitherto. There is more 'bottom-up' politics making local communities feel stronger.

\section{The New Phase}

These factors cause the mechanisms in the old model, while still continuing in effect, to be accompanied now by an entirely greater emphasis on sharing with the local community, embodied in a host of new mechanisms, procedures, and expectations. The characteristics of this new phase are displayed in the many examples we found globally.

- Local impact and benefit agreements, or community benefit agreements, are becoming widespread. In the past, impact and benefit agreements have been put in place for small isolated communities in northern Canada, often aboriginal communities, as Alastair Lucas (Chapter 19) explains. But what is startling is that we find them everywhere now, not only in isolated communities. For example, wind turbine developments in settled localities in developed countries are now often approved with community benefit agreements, as LeRoy Paddock and Max 
Greenblum (Chapter 9) document. In Britain, shale gas operators are making local benefits commitments of about $£ 100,000$ per well and $1 \%$ of revenues if any.

- Wind energy is now being developed on a massive scale in many countries. Wind turbines are often very novel in the landscape, and that causes controversy. In the United States, Community Benefit Agreements (CBAs) have become common as a way to help get projects approved. Paddock and Greenblum show that CBAs had their origins in hazardous waste landfill projects. They might deal with particular adverse effects, guarantee employment, or promise amenities like parks, schools, and clinics. Some are voluntary, some are governmentmandated (eg in the state of Maine), and some are encouraged by the permitting process. Some simply pay money to the affected community, often $\$ 4000$ per turbine per annum.

- $\quad$ Some community benefits are reaped by community ownership. In Denmark, as Anita Rønne (Chapter 10) shows, wind developers are already obliged to offer a $20 \%$ ownership stake to individuals within $4.5 \mathrm{~km}$ of a project. This may be copied in the United Kingdom. The UK already sees a pattern of cash payments to community funds. Aileen McHarg (Chapter 17) demonstrates that in Scotland such benefits packages have become standard. Similar funds are used in the Netherlands, and participation plans are compulsory; see Martha Roggenkamp (Chapter 11).

- $\quad$ Crowdfunding is a new route to community ownership, explored by Catherine Banet (Chapter 18) of small-scale community energy projects.

- Community benefits and individual compensation benefits are sometimes 'forced' (to use Alistair Lucas's words in Chapter 19) in Canada by the use of permitting procedures that ostensibly have no power to require such benefits. Regulatory participation rights therefore conjointly produce community benefits.

- $\quad$ Regulatory participation rights remain important but controversial in addressing NIMBY issues in China (Wang Mingyuan and Li Bin in Chapter 21) and environmental issues more generally in India (Lavanya Rajamani and Shibani Ghosh in Chapter 22).

- Environmental restoration funds are in some countries put under the control of local communities. As Nonye Opara shows (Chapter 13), they provide financial assurance for environmental compensation and restoration, and therefore ensure that costs are properly shared as well as benefits. Bankes and Kalkbrenner also address financial assurance for compensation (Chapter 12).

- In Australia, mining companies make important agreements with aboriginal groups which have a 'right to negotiate' conferred by the Native Title Act. Lee Godden and Lily O'Neill explore these agreements in Chapter 8. In Chapter 5, Lila Barrera-Hernandez analyzes the implementation in South America of the important principle 'free prior and informed consent' of indigenous peoples.

- Heritage funds are established in a number of oil or mineral producing countries, such as Norway and Mexico, in order to hold oil revenues on trust. The new Mexican legislation that provides for payments to local communities for health, education, family, and labour development is explained and critiqued by José Juan González in Chapter 14. At the non-community end of the spectrum, the 
Alaska Permanent Fund has for decades made payments from oil revenue directly to individual residents of the state.

- $\quad$ Royalty distribution and allocation systems have changed. In Brazil oil revenues are shared by the federal government with oil producing states and municipalities, but recent reforms to direct more money to non-producing regions have met with opposition. Yanko Marcius de Alençar Xavier and Anderson Souza da Silva Lanzillo give an account of these reforms in Chapter 16. In other countries in South America, a portion of the mineral royalties revenue is set aside for health and education, but it has sometimes been difficult to allocate. In Chapter 15, Yinka Omorogbe chronicles the arduous process of petroleum law reform in $\mathrm{Ni}$ geria.

- In Colombia, local authorities (both regional and municipal bodies) have made claims, evaluated by Milton Montoya in Chapter 20, to participate in the regulation of mining, relying on a constitutional principle of local autonomy.

- This new phase is often described as one of 'social licence to operate.' Don Smith gives the concept close examination in Chapter 7 in the context of unconventional oil and gas operations in Colorado in the United States. Social licence to operate is often vital. If a company wants a smooth run through its permitting procedures and some reassurance that the legislature will not simply ban fracking, then it needs social licence.

- $\quad$ Corporate Social Responsibility is directly connected. For example, mining in South Africa is now the subject of an elaborate legal framework requiring corporate social responsibility. Hanri Mostert and a team of co-authors explore it in detail in Chapter 6.

- $\quad$ There have been success stories in many countries where large energy and resources projects have gone ahead enjoying good relationships with their host communities. Don Zillman, Simon Beirne and Elizabeth Elsbach in Chapter 23 reflect on how a "big project in a small town" can work well if people see real benefits collectively and individually, and where the project can generate and maintain a super-majority of public support and a perception that negative effects of the project are a shared problem. Martha Roggenkamp in Chapter 11 tackles similar issues in the Netherlands.

The book's chapters provide examples from energy and resource sectors, emerging technologies, and renewable energy sources. They examine situations across all phases of energy and resource activity from funding of projects to project closure. Many chapters explore the range of legal measures and regulatory frameworks for sharing the costs and benefits of energy and resource development. They offer insights into how concepts of community, and indeed law and governance, are shaped through the relationships that arise between communities and those involved with energy and resource projects. Local communities of all kinds are much more alert to the destination of benefits from oil and gas projects, shale oil and gas, mining projects, wind farms, hydroelectric dams, and electricity transmission lines. They are much more alert to the costs that may be imposed on them, especially risks, especially social costs. With some projects, such as renewable energy, carbon capture and storage, or nuclear waste storage, the benefits are very diffuse but the costs or risks are very local. In many countries, the law has progressively provided stronger recognition of indigenous peoples' rights; again, often with consequences for the regulation of energy and resource projects, and ultimately for the 
sharing of costs and benefits. But it is striking how widespread in all kinds of context the impetus for sharing cost and benefits has become.

The importance of sharing costs and benefits can scarcely be overstated. Sharing and allocation are fundamentally questions of justice and of the legitimate exercise of power in society. Good laws and good political processes can produce better outcomes that promote peace, equity, and social justice. This study demonstrates that in pursuing such outcomes lawmakers have a substantial range of options and depth of insight with which to inform their choices. 